NBER WORKING PAPER SERIES

\title{
INTEGRATION AND INFORMATION: \\ MARKETS AND HIERARCHIES REVISITED
}

\author{
Robert S. Gibbons \\ Richard T. Holden \\ Michael L. Powell \\ Working Paper 15779 \\ http://www.nber.org/papers/w15779 \\ NATIONAL BUREAU OF ECONOMIC RESEARCH \\ 1050 Massachusetts Avenue \\ Cambridge, MA 02138 \\ February 2010
}

We thank Daron Acemoglu, Philippe Aghion, Mathias Dewatripont, Glenn Ellison, Oliver Hart, Bengt Holmstrom, Birger Wernerfelt, Oliver Williamson, and seminar participants at Chicago, Harvard, MIT, Northwestern, Queen's, Toronto and USC for helpful comments. All three authors thank MIT Sloan's Program on Innovation in Markets and Organizations for financial support, and Powell also thanks the NSF. The views expressed herein are those of the authors and do not necessarily reflect the views of the National Bureau of Economic Research.

NBER working papers are circulated for discussion and comment purposes. They have not been peerreviewed or been subject to the review by the NBER Board of Directors that accompanies official NBER publications.

(C) 2010 by Robert S. Gibbons, Richard T. Holden, and Michael L. Powell. All rights reserved. Short sections of text, not to exceed two paragraphs, may be quoted without explicit permission provided that full credit, including $(\mathcal{O}$ notice, is given to the source. 
Integration and Information: Markets and Hierarchies Revisited

Robert S. Gibbons, Richard T. Holden, and Michael L. Powell

NBER Working Paper No. 15779

February 2010

JEL No. D2,D23

\begin{abstract}
$\underline{\text { ABSTRACT }}$
We analyze a rational-expectations model of price formation in an intermediate-good market under uncertainty. There is a continuum of dyads, each consisting of an upstream party and a downstream party. Both parties can make specific investments at private cost, and there is a machine that either party can own. As in property-rights models, different ownership structures create different incentives for the parties' investments. As in rational-expectations models, some parties may invest in acquiring information, which is then incorporated into the market-clearing price by the parties' trading behaviors. The informativeness of the price mechanism affects the returns to specific investments and hence the optimal ownership structure for individual dyads; meanwhile, the ownership choices by individual dyads affect the informativeness of the price mechanism. In equilibrium the informativeness of the price mechanism can induce ex ante homogenous dyads to choose heterogeneous ownership structures.
\end{abstract}

Robert S. Gibbons

Sloan School of Management

E52-432

MIT

Cambridge, MA 02142

and NBER

rgibbons@mit.edu

Richard T. Holden

University of Chicago

Booth School of Business

Room 528

5807 S Woodlawn Ave

Chicago,IL 60637

and NBER

richard.holden@chicagobooth.edu
Michael L. Powell

MIT

mlp@mit.edu 


\section{Introduction}

Since Coase (1937), economists have sought to understand why firms exist, given the power of the price mechanism as an informing and coordinating device. As Coase argued, "it is surely important to enquire why co-ordination is the work of the price mechanism in one case and of the entrepreneur in the other" (p. 359, emphasis added).

Significant progress has been made in answering this question, including contributions by Williamson (1971, 1975, 1979), Klein, Crawford and Alchian (1978), Grossman and Hart (1986), Hart and Moore (1990), and others. But, while Coase was explicit that the "price mechanism" is the chief alternative to internal organization, and Williamson's (1975) title famously emphasized "Markets" as the alternative to hierarchy, over the next 35 years, the market disappeared from the literature on firms' boundaries. Instead, the literature focused on non-integration versus integration at the transaction level, rather than the functioning of the price mechanism at the market level.

Omitting the price mechanism from the theory of the firm could be problematic. In particular, suppose (as seems plausible in the world and is being explored in a growing theoretical literature) that agents choose firm boundaries and internal control structures in part to affect incentives to gather and communicate information. ${ }^{1}$ Agents' interests in choosing governance structures to strengthen these incentives will depend in part on how well market prices already perform this function. For example, if market prices are very informative, then agents will choose governance structures to improve incentives for other activities (say, cost reduction), effectively free-riding on the informativeness of the price mechanism. On the other hand, as Grossman and Stiglitz (1980) noted long ago, if everyone free-rides, then there will not be any information in prices. Thus, analyzing the choice between integration and non-integration for one dyad in isolation (rather than in the context of a market of analogous dyads making analogous choices) potentially commits two errors.

\footnotetext{
${ }^{1}$ For example, see Milgrom \& Roberts (1988), Holmstrom \& Tirole (1991) and Aghion \& Tirole (1997) for early work, and Alonso et al. (2008) and Rantakari (2008) as a sample of recent work.
} 
First, each dyad takes the informativeness of the price mechanism as an important parameter in its choice of governance structure, but this parameter is hard to discern in most models of the integration decision. And second, this important parameter is endogenous: agents' governance-structure decisions affect the informativeness of the price mechanism.

We view firms and the market not only as alternative ways of organizing economic activity, but also as institutions that shape each other. In this paper we explore how the informativeness of the price mechanism and firms' integration decisions interact. To do so we analyze an economic environment that includes uncertainty. Formally, the uncertainty concerns consumers' valuation of final goods, but we discuss other interpretations below. Parties can resolve this uncertainty at a cost. As in other rational-expectations models, the price mechanism both clears the market and conveys information from informed to uninformed parties. The fact that the price is not perfectly informative provides the requisite incentive for some parties to pay the cost to resolve the uncertainty.

As one specific example, consider a U.S. steel producer deciding how much steel to produce. Demand for steel might depend on future construction in China, which is uncertain. Travelling to China and conducting interviews could give a steel producer a better signal of Chinese construction and hence demand for steel. But other steel producers, who choose not to conduct such research, could look at the market price for an upstream good (such as iron ore) and infer some of the information gathered by the firms that did conduct research. This example parallels our model, in that it is the market-clearing price of an upstream good (iron ore) that conveys information about the uncertain value of the downstream good (steel).

Many other applications of our approach arise if we consider alternative sources of uncertainty, other than the value of goods such as steel. For example, the uncertainty might concern whether tariff barriers will change or whether a new technology will fulfill its promise. Interestingly, however, not all sources of uncertainty will do: our rational-expectations model applies to common (or partially correlated)- rather than private-value uncertainty. As Gross- 
man (1981: 555) puts it, in non-stochastic economies (and certain economies with privatevalue uncertainty), "No one tries to learn anything from prices [because] there is nothing for any individual to learn." Often, however, there is something to learn from prices, such as when there is common-value uncertainty.

To pursue these issues, we develop a rational-expectations model similar to Grossman and Stiglitz $(1976,1980)$ but designed to apply to a market for an intermediate good (prices and net supply are non-negative and the players are risk-neutral). In Gibbons, Holden, and Powell (2009; hereafter GHP), we developed such a model but for the Grossman-Stiglitz case of individual investors. The novel aspect of the present paper is the analysis of alternative governance structures. Specifically, we allow for production by dyads (where control can be allocated to either party) rather than by individual investors. Relative to rationalexpectations pricing models such as Grossman-Stiglitz (and GHP), the novel component in this paper is the analysis of alternative governance structures. Specifically, we enrich GHP to allow for production by dyads rather than only individual investors.

To model these dyads, we develop a simplified version of the classic property-rights theory (PRT) initiated by Grossman and Hart. To keep things simple, our property-rights model involves only a single alienable asset and hence two governance structures. Regardless of who owns the asset, each party can make a specific investment, but the incentives to make these investments depend on who owns the asset. Following the PRT (i.e., analyzing one dyad in isolation) reveals that the optimal ownership structure is determined by the marginal returns to these investments. In our model all dyads are homogeneous ex ante, so a PRT analysis of a single dyad would prescribe that all dyads choose the same ownership structure. Relative to the PRT, the novel component of our model is the informativeness of the price mechanism, which endogenizes the returns to the parties' specific investments and hence creates an industry-level determinant of an individual dyad's choice of governance structure.

In summary, our model integrates two familiar approaches: rational expectations (where an imperfectly informative price mechanism both permits rational inferences by some parties 
and induces costly information acquisition by others) and property rights (where equilibrium investments depend on the parties' governance structure and asset ownership is chosen to induce second-best investments). Our main results are that: (1) when dyads choose firm boundaries they affect incentives to gather information, and (2) the informativeness of the price mechanism is a central determinant of whether dyads choose boundaries to strengthen these incentives (or, instead, make decisions to strengthen other incentives, such as for cost reduction), and this informativeness is endogenously determined by the aggregation of dyads' governance-structure choices in market equilibrium. In fact, in our model, certain governance structures may be sustained in market equilibrium only because the price system allows some firms to benefit from the information-acquisition investments of others.

Grossman \& Helpman (2002), Legros \& Newman (2008) and Legros \& Newman (2009) analyze other interactions between firms' integration decisions and the market, focusing on interactions that do not involve the informativeness of the price mechanism. In these models, supply and demand determine prices, which in turn determine the returns to the parties' actions and hence the parties' optimal governance structures; meanwhile, the parties' actions in turn determine supply and demand, so governance and pricing interact. As Grossman (1981: 555) notes, such Walrasian equilibria are not useful "as a tool for thinking about how goods are allocated... when...information about the future...affects current prices." In contrast to the aforementioned papers, our model focuses of the informative role of prices: transferring information from informed to (otherwise) uninformed parties. We see these two approaches as complementary. Indeed, in economies with uncertainty the price mechanism plays two roles: it clears the market and communicates information.

The remainder of the paper proceeds as follows. In Section 2 we specify and discuss the model. Section 3 analyzes the integration decision of a single dyad in isolation, and Section 4 analyzes the informativeness of the price mechanism, taking firms' governance structure choices as given. Section 5 then combines the property-rights and rational-expectations aspects of the previous two sections, analyzing the equilibrium choices of governance structures 
for all the dyads in the industry and hence deriving our main results. Section 6 discusses some implications of the model and Section 7 concludes.

\section{The Model}

\subsection{Overview of the Model}

We begin with an informal description of our model. There is a continuum of dyads, each consisting of upstream and downstream parties in a production process that can transform an intermediate good (a "widget") into a final good. Upstream parties may be endowed with a widget. Upstream parties that are endowed with a widget can sell it in the widget market, and any party may purchase a widget from the market. There is an alienable asset (a machine) that can transform one widget into one final good at a cost. Upstream parties may make investments that reduce the cost of operating the machine; we therefore think of upstream parties as having human capital that is relevant to the production of final goods. Downstream parties may make investments that deliver information about the value of a final good in the consumer market; we therefore think of downstream parties as having human capital that is relevant to the marketing of final goods.

As in the PRT, the parties' incentives to make investments depend on asset ownership. In particular, in our model, only the party that owns the machine has an incentive to invest. Thus, in dyads where the downstream party owns the machine, the downstream party invests in information about the value of the final good, whereas in dyads where the upstream party owns the machine, the upstream party invests instead in cost reduction and relies solely on the price mechanism for information about the value of the final good. Naturally, if the price mechanism is more informative, the returns to investing in information are lower so dyads have a greater incentive to choose upstream ownership and invest instead in cost reduction. As in rational-expectations models, however, when fewer parties invest in information, the price mechanism becomes less informative, thereby making downstream ownership more 
attractive. An industry equilibrium must balance these two forces. We show that a unique equilibrium exists and is often interior. In this sense, the price mechanism induces heterogenous behavior among homogeneous dyads.

\subsection{Statement of the Problem}

There is a unit mass of risk-neutral dyads that are exogenously matched to each other. Each dyad $i \in[0,1]$ consists of two parties, denoted $U_{i}$ and $D_{i}$, and a machine that is capable of developing one intermediate good (a "widget") into one final good at cost $c_{i} \sim U[\underline{c}, \bar{c}]$. The machine can be owned by either party, but it is relationship-specific (i.e., the machine is useless outside its intended dyad). If party $U_{i}$ owns the machine, we say that the governance structure in dyad $i$ is $g_{i}=U$, whereas if party $D_{i}$ owns the machine, we say that $g_{i}=D$.

Final goods have an uncertain value. Party $D_{i}$ can invest at private cost $K_{D}$ to learn the value of a final good in the market, $v \sim U[\underline{v}, \bar{v}]$. If $D_{i}$ incurs this cost, $U_{i}$ knows that $D_{i}$ is informed but does not herself observe $v$. Party $U_{i}$ can invest at cost $K_{U}$ in reducing the cost of operating the dyad's machine. If she incurs this cost, both parties observe that $c_{i}$ is reduced to $c_{i}-\Delta$, where $\Delta \leq \underline{c}$.

We embed these dyads in our rational-expectations model of price formation in goods markets from GHP. A fraction $y \leq 1$ of the dyads is endowed with a widget. In particular, $U_{i}$ is endowed with $w_{i}=1$ widget if $i \leq y$ and $w_{i}=0$ widgets if $i>y$, where $y$ is taken to be an exogenous (and commonly known) aggregate endowment. Parties not endowed with a widget may purchase one in the widget market, and those who are endowed with one may sell it into the market. Additionally, there is a set of firms outside this industry of uncertain mass $z$, each of whom demands one widget inelastically at any price $p \leq \bar{v}$. We think of this demand as coming from a "nearby" industry that has an alternative use for widgets. Assume $z \sim U[\underline{z}, \bar{z}]$, and define $x=y-z \sim U[\underline{x}, \bar{x}]$ to be the net endowment of widgets in the industry we analyze (where $\underline{x}=y-\bar{z}$ and $\bar{x}=y-\underline{z}$ are such that $[\underline{x}, \bar{x}] \subseteq[0,1]$ ).

Equilibrium in the market for widgets occurs at the price $p$ that equates supply and 
demand (from informed, uninformed, and outside parties). In making supply or demand decisions for widgets, parties that are not directly informed about $v$ make rational inferences about $v$ from the market price for widgets. Dyads choose their governance structures (i.e., machine ownership) taking into account the information that will be inferred from the market price and hence the relative returns from the two parties' investments.

\subsection{Timing and Assumptions}

We now state the timing and assumptions of the model more precisely. We comment on these assumptions in Section 2.3. There are seven periods.

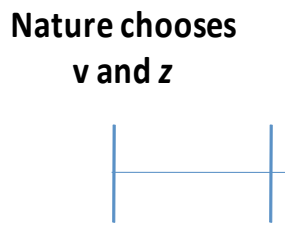

Dyads choose governance structure

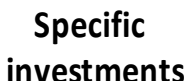

investments

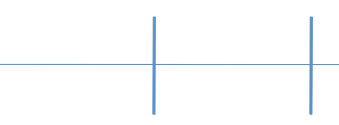

Widget endowment
Price formation

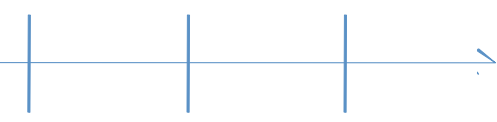

Figure 1: Timeline

In the first period, industry-level uncertainty is resolved: the value of a final good $v$ is drawn from $U[\underline{v}, \bar{v}]$ and the outside demand $z$ is drawn from $U[\underline{z}, \bar{z}]$, but neither of these variables is observed by any parties.

In the second period, each dyad negotiates a governance structure $g_{i} \in\{U, D\}$ : under $g_{i}=U$, party $U_{i}$ owns the machine that can develop one widget into one final good; under $g_{i}=$ $D$, party $D_{i}$ owns this machine. This negotiation of governance structure occurs via Nash bargaining. To simplify notation, we assume that dyads do not know their indices at this point and hence cannot condition their governance-structure choices on their endowments.

In the third period, parties $U_{i}$ and $D_{i}$ simultaneously choose whether to make relationship specific investments (or not) at costs $K_{U}$ and $K_{D}$, respectively. In partial accordance with the PRT, we assume that the acts of making these investments are observable but not verifiable, 
but we depart from the PRT (in a manner that is natural in our setting) by assuming that the outcome of the downstream party's investment (namely, learning $v$ ) is observable to only $D_{i}, \operatorname{not} U_{i}$

In the fourth period, each dyad learns its index, $i$, and all $U_{i}$ with $i \leq y$ are endowed with $w_{i}=1$ widget.

In the fifth period, price formation takes place, in three steps. In period $5 \mathrm{a}$, the parties $U_{i}$ and $D_{i}$ commonly observe $c_{i} \sim U[\underline{c}, \bar{c}]$, the raw cost of running their machine, as well as $\delta_{i} \in\{0, \Delta\}$, the amount of cost reduction achieved by $U_{i}$ 's specific investment. Also, $D_{i}$ (but not $U_{i}$ ) observes $\varphi_{i} \in\{\emptyset, v\}$, a signal about the value $v$ of the final good, where $\varphi_{i}=\emptyset$ is the uninformative signal that obtains if party $D_{i}$ has not invested $K_{D}$ in period 3 , and $\varphi_{i}=v$ is the perfectly informative signal received if $K_{D}$ has been invested. It is useful to introduce the following notation for the parties' information sets: $s_{i}^{D}=\left(c_{i}, \delta_{i}, \varphi_{i}\right), s_{i}^{U}=\left(c_{i}, \delta_{i}, \emptyset\right)$, and $s_{i}=\left(s_{i}^{D}, s_{i}^{U}\right)$. Then, in period 5b, a mass $z$ of outside parties each demands a single widget at any price $p \leq \bar{v}$. Finally, in period $5 \mathrm{c}$, the market for widgets clears at price $p$. In particular, any party may buy a widget, and any upstream party endowed with a widget may sell it (inside or outside the dyad). There are thus eight possible outcomes when the market closes, depending on whether upstream has a widget, downstream has a widget, and who owns the machine. As the analysis in Section 4 shows, however, the only relevant issue is whether the machine owner has a widget.

In the sixth period, production occurs: if the machine owner in dyad $i$ has a widget, then he or she can run the machine to develop the widget into a final good at $\operatorname{cost} c_{i}-\delta_{i}$. We denote the decision to produce a final good by $q_{i}=1$ and the decision not to do so by $q_{i}=0$. Off the equilibrium path, one party might own the machine and the other a widget, in which case the parties bargain over the widget and then the machine owner makes the production decision. 
Finally, in the seventh period, final goods sell for $v$ and payoffs are realized. The expected payoffs (before $v$ is realized) are

$$
\begin{gathered}
\pi_{U_{i}}^{g_{i}}=p w_{i}+1_{\left\{g_{i}=U\right\}} 1_{\left\{q_{i}=1\right\}}\left[E\left[v \mid s_{i}^{U}, p(\cdot, \cdot)=p\right]-p-\left(c_{i}-\delta_{i}\right)\right], \text { and } \\
\pi_{D_{i}}^{g_{i}}=1_{\left\{g_{i}=D\right\}} 1_{\left\{q_{i}=1\right\}}\left[E\left[v \mid s_{i}^{D}, p(\cdot, \cdot)=p\right]-p-\left(c_{i}-\delta_{i}\right)\right] .
\end{gathered}
$$

\subsection{Discussion of the Model}

Before proceeding with the analysis, we pause to comment on some of the modeling choices we have made.

First, we assume that the machine is dyad-specific. This assumption allows us to focus on the market for widgets by eliminating the market for machines. By allowing both markets to operate, one could analyze whether the informativeness of one affects the other.

Second, we have only one alienable asset, in contrast to the classic PRT setting. Our choice here is driven purely by parsimony; extending the model to allow more alienable assets (and hence more governance structures) could be interesting.

Third, we have binary investments in cost reduction and information acquisition (at costs $K_{U}$ and $K_{D}$, respectively), rather than continuous investment opportunities. It seems straightforward to allow the probability of success (in cost reduction or information acquisition) to be an increasing function of the investment level, which in turn has convex cost.

Fourth, we assume that the exogenous aggregate endowment $y$ is known and whether an individual dyad receives a widget is not revealed until period 4. The exogeneity of $y$ eliminates inferences about aggregate endowments based on individual endowments. Revealing individual endowments in period 4 eliminates conditioning the choices of governance structure or specific investments on the dyad's endowment. The latter is not a substantive assumption (since $w_{i}$ enters additively everywhere), but we make it for notational simplicity.

Fifth, as in GHP, we assume inelastic demand $z$ from an outside industry at any price 
$p \leq \bar{v}$. This uncertain demand plays the role of noise traders, making the market price for widgets only partially informative about $v$, so that parties may benefit from costly acquisition of information about $v$.

Sixth, again as in GHP, our assumptions that all the random variables are uniform allow us to compute a closed-form (indeed, piece-wise linear) solution for the equilibrium price function at the industry level. This tractability is very useful in the computing the returns to alternative governance structures, at the dyad level.

Seventh, as in Grossman-Stiglitz and the ensuing rational-expectations literature, our model of price formation is not an extensive-form model of strategic decision-making (including information transmission during the price-formation process), but rather a reduced-form model of price-taking behavior. See GHP for an extended discussion.

\section{Individual Dyad Behavior}

As a building block for our ultimate analysis, we first analyze the behavior of a single dyad taking the market price $p$ as given. To begin, define the expected gross surplus (at the start of period seven) for dyad $i$ as

$$
\begin{aligned}
G S_{i}+p w_{i} & =\pi_{U_{i}}^{g_{i}}+\pi_{D_{i}}^{g_{i}} \\
& =p w_{i}+1_{\left\{q_{i}=1\right\}}\left[E\left[v \mid s_{i}^{g_{i}}, p(\cdot, \cdot)=p\right]-p-\left(c_{i}-\delta_{i}\right)\right]
\end{aligned}
$$

Therefore, in period 6 (production), the efficient production decision is $q_{i}^{*}=1$ if $E_{x, v}\left[v \mid s_{i}^{g_{i}}, p\right] \geq$ $p+c_{i}-\delta_{i}$. The maximized expected gross surplus in period 6 is then

$$
G S_{i}^{*}\left(g_{i}, s_{i}\right)=E_{x, v}\left[\left(v-c_{i}+\delta_{i}-p\right) q_{i}^{*}\left(g_{i}, s_{i}, p\right) \mid s_{i}^{g_{i}}, p\right]
$$

Working backwards, in period 5, there are three possible cases of interest. First, if $w_{i}=0$, then the party with the machine may purchase a widget at price $p$; the party who 
owns the machine then gets $G S_{i}^{*}$ and the other party obtains a zero payoff. Second, if $w_{i}=1$ and $g_{i}=U$, then $U_{i}$ may keep the widget or sell it into the market at price $p$, so she gets $G S_{i}^{*}+p$ and $D_{i}$ obtains a zero payoff. Finally, if $w_{i}=1$ and $g_{i}=D$, then the parties bargain over whether to transfer the widget from $U_{i}$ to $D_{i}$ and at what price. Since $U_{i}$ can sell the widget on the market at price $p$, and $D_{i}$ can buy a widget at $p$, any plausible bargaining protocol leads to the result that the widget will be traded from $U_{i}$ to $D_{i}$ at price $p$, an illustration of the Law of One Price, so $U_{i}$ receives $p$ and $D_{i}$ obtains $G S_{i}^{*}$. In sum, in all three cases, the machine owner receives $G S_{i}^{*}$ and the non-owner receives a constant. These payoffs determine the parties' investment incentives in period 3, as follows.

Let the subscript pair $(I, 0)$ denote the situation in which $D_{i}$ invested and hence is informed about $v$ but $U_{i}$ did not invest in cost reduction, $(U, \Delta)$ the situation in which $D_{i}$ did not invest but $U_{i}$ did, hence reducing production costs by $\Delta$, and $(U, 0)$ the situation in which neither invested. Now define the following:

$$
\begin{aligned}
\pi_{I, 0} & =E_{c_{i}}\left[G S_{i}^{*}\left(D, s_{i}\right)\right] \text { if } \varphi_{i}=v, \delta_{i}=0, \\
\pi_{U, \Delta} & =E_{c_{i}}\left[G S_{i}^{*}\left(U, s_{i}\right)\right] \text { if } \varphi_{i}=\emptyset, \delta_{i}=\Delta, \text { and } \\
\pi_{U, 0} & =E_{c_{i}}\left[G S_{i}^{*}\left(g_{i}, s_{i}\right)\right] \text { if } \varphi_{i}=\emptyset, \delta_{i}=0 .
\end{aligned}
$$

Formally, these expectations are triple integrals over $\left(c_{i}, x, v\right)$ space:

$$
\begin{gathered}
\pi_{I, 0}=\int_{\underline{v}}^{\bar{v}} \int_{\underline{x}}^{\bar{x}} \int_{\underline{c}}^{v-p(x, v)}\left(v-p(x, v)-c_{i}\right) d F\left(c_{i}, x, v\right), \\
\pi_{U, \Delta}=\int_{\underline{v}}^{\bar{v}} \int_{\underline{x}}^{\bar{x}} \int_{\underline{c}}^{E[v \mid p]-p(x, v)+\Delta}\left(v-p(x, v)+\Delta-c_{i}\right) d F\left(c_{i}, x, v\right), \text { and } \\
\pi_{U, 0}=\int_{\underline{v}}^{\bar{v}} \int_{\underline{x}}^{\bar{x}} \int_{\underline{c}}^{E[v \mid p]-p(x, v)}\left(v-p(x, v)-c_{i}\right) d F\left(c_{i}, x, v\right),
\end{gathered}
$$

where $F$ is the joint distribution function.

Since one party's expected payoff in period 5 is independent of its investment, at most one 
party will invest in period 3. If $U_{i}$ owns the machine $\left(g_{i}=U\right)$, she will invest if $\pi_{U, \Delta}-K_{U} \geq$ $\pi_{U, 0}$. Similarly, if $D_{i}$ owns the machine $\left(g_{i}=D\right)$, he will invest if $\pi_{I, 0}-K_{D} \geq \pi_{U, 0}$. We assume that $K_{U}$ and $K_{D}$ are small relative to the benefits of investment, so at least one party will invest. ${ }^{2}$

To proceed, we need to compute the price function $p(x, v)$. This involves analyzing the behavior of other dyads, and it is to this task that we now turn.

\section{Rational Expectations in the Market for Intermedi- ate Goods}

Recall that there is a unit mass of dyads indexed by $i \in[0,1]$. Who sells on the market and who buys? Dyads with sufficiently low development costs $\left(c_{i}\right)$ and no widget may purchase one, and dyads with a widget and sufficiently high development costs may sell one. Define $c_{D}(v, p)=v-p$ to be the highest cost at which a downstream party that has invested in information (and hence knows $v$ ) would be prepared to produce a final good, and similarly let $c_{U}(p)=E[v \mid p]-p+\Delta$ be the highest cost at which an upstream party that has invested in cost reduction (but not information) would be prepared to produce. Supposing (as we will endogenize below) that a fraction $\lambda$ of dyads have $D$ ownership (and hence know $v$ ), whereas fraction $1-\lambda$ have $U$ ownership (and hence costs reduced by $\Delta$ ), the buyers and sellers of widgets are then illustrated in the following diagram.

\footnotetext{
${ }^{2}$ This condition can be stated in terms of primitives of the model, but since this is the economic assumption we are making, we state it in this fashion.
} 


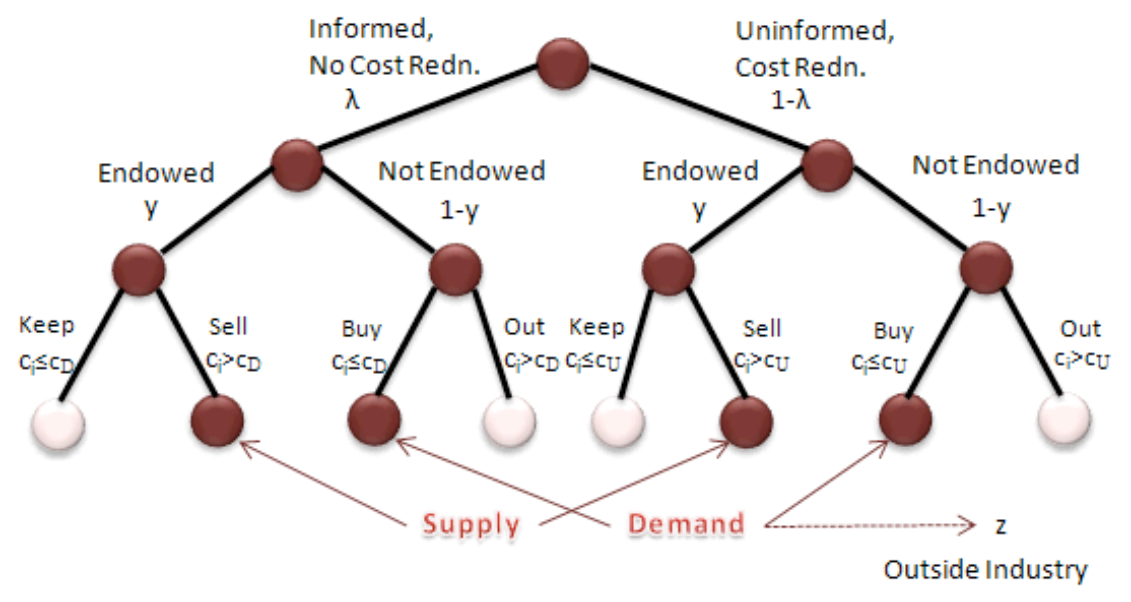

Figure 2: Supply and Demand

Formally, dyad $i$ sells on the market if it receives a widget (which occurs for a mass $y$ of dyads) and its development $\operatorname{costs} c_{i}-\delta_{i}$ are too high to warrant production (i.e., $\left.E_{x, v}\left[v \mid s_{i}, p\right]-p<c_{i}-\delta_{i}\right)$. Similarly, dyad $i$ buys on the market if it does not receive a widget (which occurs with probability $1-y$ ) and its development costs are sufficiently low (i.e., $E_{x, v}\left[v \mid s_{i}, p\right]-p \geq c_{i}-\delta_{i}$ ). Then, since ex ante investment incentives are identical for all dyads, supply of widgets is given by

$$
\begin{aligned}
& y \operatorname{Pr}\left[E_{x, v}\left[v \mid s_{i}, p(x, v)=p\right]-p<c_{i}-\delta_{i}\right] \\
& =y\left[\begin{array}{c}
\lambda \operatorname{Pr}\left[v-p<c_{i}\right] \\
+(1-\lambda) \operatorname{Pr}\left[E[v \mid p(x, v)=p]-p<c_{i}-\Delta\right]
\end{array}\right] \\
& =y\left[1-\lambda \frac{v-p-\underline{c}}{\bar{c}-\underline{c}}-(1-\lambda) \frac{E[v \mid p(x, v)=p]+\Delta-p-\underline{c}}{\bar{c}-\underline{c}}\right],
\end{aligned}
$$

and demand for widgets is given by 


$$
\begin{aligned}
& (1-y) \operatorname{Pr}\left[c_{i}-\delta_{i} \leq E_{x, v}\left[v \mid s_{i}, p(x, v)=p\right]-p\right] \\
& =(1-y)\left[\lambda \operatorname{Pr}\left[c_{i} \leq v-p\right]+(1-\lambda) \operatorname{Pr}\left[c_{i}-\Delta \leq E[v \mid p(x, v)=p]-p\right]\right] \\
& =(1-y)\left[\lambda \frac{v-p-\underline{c}}{\bar{c}-\underline{c}}+(1-\lambda) \frac{E[v \mid p(x, v)=p]+\Delta-p-\underline{c}}{\bar{c}-\underline{c}}\right]
\end{aligned}
$$

from inside the industry as well as $z$ from the outside industry. The market-clearing price equates demand and supply, so substituting $x=y-v$ yields

$$
p=(1-\lambda) E[v \mid p(x, v)=p]+\lambda v-(\bar{c}-\underline{c}) x+(1-\lambda) \Delta-\underline{c} .
$$

The conditional expectation of $v$ given $p$ therefore must satisfy

$$
E[v \mid p(\cdot, \cdot)=p] \equiv \frac{p+(\bar{c}-\underline{c}) x+\underline{c}-(1-\lambda) \Delta-\lambda v}{1-\lambda},
$$

where the equivalence relation reminds us that (1) must hold as an identity in $x$ and $v$.

Definition 1 Assume fractions $\mu_{I \Delta}, \mu_{I 0}, \mu_{U \Delta}, \mu_{U 0}$ of dyads are, respectively, informed and have cost reduction, informed and do not have cost reduction, uninformed and have cost reduction, and uninformed and do not have cost reduction. Let $\mu=\left(\mu_{I \Delta}, \mu_{I 0}, \mu_{U \Delta}, \mu_{U 0}\right) . \quad A$ rational expectations equilibrium ("REE") is a price function $p(x, v)$ and a production allocation $\left\{q_{i}\right\}_{i \in[0,1]}$ such that

1. $q_{i}=q_{i}^{*}\left(q_{i}, s_{i}, p\right)$ for all $i$, and

2. The market for widgets clears for each $(x, v) \in[\underline{x}, \bar{x}] \times[\underline{v}, \bar{v}]$.

The above analysis implies $\mu_{I \Delta}=0$, and $K_{U}$ and $K_{D}$ small implies $\mu_{U 0}=0$. Let $\lambda=\mu_{I 0}$ and $1-\lambda=\mu_{U \Delta}$. The problem of finding a rational-expectations price function in this model becomes one of finding a fixed point of (1). In GHP, we solve for this fixed point, finding it 
to be piecewise-linear over three regions of $(x, v)$ space: a low-price region, a moderate-price region, and a high-price region.

Proposition 1 Given $\lambda$, there exists an REE characterized by a price function

$$
p(x, v)=1_{\left\{(x, v) \in R_{\lambda}^{1}\right\}} p^{1}(x, v)+1_{\left\{(x, v) \in R_{\lambda}^{2}\right\}} p^{3}(x, v)+1_{\left\{(x, v) \in R_{\lambda}^{3}\right\}} p^{3}(x, v),
$$

where $p^{j}(x, v)=\beta_{0}^{j}+\beta_{1}^{j} x+\beta_{2}^{j} v$ for $j=1,2,3$.

To build some intuition for this result, consider the figure below, which shows the three regions of $(x, v)$ space, $R_{\lambda}^{j}$ for $j=1,2,3$. The low-price region $R_{\lambda}^{1}$ begins from the lowest feasible price, $p_{L}$ at $(\bar{x}, \underline{v})$, and extends up to the price $\bar{p}$ at $(\bar{x}, \bar{v})$. The moderate-price region $R_{\lambda}^{2}$ then extends from price $\bar{p}$ up to the price $\underline{p}$ at $(\underline{x}, \underline{v})$, and the high-price region $R_{\lambda}^{3}$ extends from $\underline{p}$ up to the highest feasible price, $p_{H}$ at $(\underline{x}, \bar{v})$.

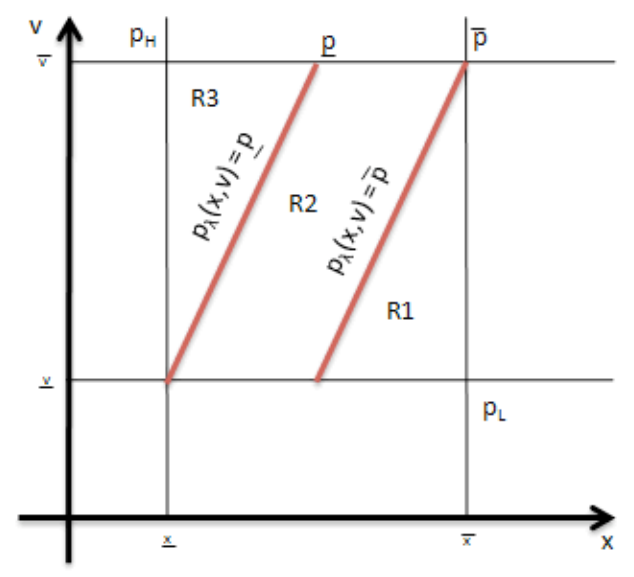

Figure 3: Regions of Piecewise-Linear Pricing Function

Within each region, the iso-price loci are linear. In particular, solving $p^{j}(x, v)=p$ for $v$ yields

$$
v=-\frac{\beta_{j}^{1}}{\beta_{j}^{2}} x+\frac{p-\beta_{j}^{0}}{\beta_{j}^{2}}
$$

as an iso-price line in $(x, v)$ space. Because $x$ and $v$ are independent and uniform, every $(x, v)$ point on this line is equally likely. Thus, after observing $p$, an informed party projects this 
line onto the $v$-axis and concludes that the conditional distribution of $v$ given $p$ is uniform, with support depending on which region $p$ is in. For example, if $p<\bar{p}$ then the lower bound on $v$ is $\underline{v}$ and the upper bound is some $\bar{v}(p)<\bar{v}$. Alternatively, if $\bar{p}<p<p$ then the lower and upper bounds on $v$ are $\underline{v}$ and $\bar{v}$, so $p$ is uninformative. Finally, if $p>p$ then the lower bound is some $\underline{v}(p)>\underline{v}$ and the upper bound is $\bar{v}$.

Given this uniform conditional distribution of $v$ given $p$, the conditional expectation on the left-hand side of (1) is then the average of these upper and lower bounds on $v$. The

coefficients $\beta_{0}^{j}, \beta_{1}^{j}$, and $\beta_{2}^{j}$ can then be computed by substituting $p^{j}(x, v)$ for $p$ on both sides of (1) and equating coefficients on like terms so that (1) holds as an identity.

\section{Industry Equilibrium}

To recapitulate, Section 3 analyzed the production decision, taking $p(\cdot, \cdot)$ as exogenous, and Section 4 endogenized prices. In this section, we endogenize the governance-structure choices of each dyad and define an industry equilibrium as follows.

Definition 2 An industry equilibrium is a set of dyads of mass $\lambda^{*}$, a price function $p(x, v)$, and a production allocation $\left\{q_{i}\right\}_{i \in[0,1]}$ such that

1. Each dyad optimally chooses $g_{i}$, with a fraction $\lambda^{*}$ choosing $g_{i}=D$;

2. Each party optimally chooses whether or not to invest;

3. $q_{i}=q_{i}^{*}\left(q_{i}, s_{i}, p\right) ;$ and

4. The market for widgets clears for each $(x, v) \in[\underline{x}, \bar{x}] \times[\underline{v}, \bar{v}]$.

The choice in period 2 is between the two possible governance structures: $g_{i}=U$ or $g_{i}=D$. The ex ante expected surpluses from choosing the two governance structures are

$$
\begin{aligned}
& T S^{U}(\lambda)=\pi_{U \Delta}(\lambda)-K_{U}, \text { and } \\
& T S^{D}(\lambda)=\pi_{I 0}(\lambda)-K_{D} .
\end{aligned}
$$


In an interior equilibrium, dyads must be indifferent between the two governance structures. Thus our goal is to find $\lambda^{*}$ such that $T S^{U}\left(\lambda^{*}\right)=T S^{D}\left(\lambda^{*}\right)$ and to characterize how $\lambda^{*}$ varies as we change the parameters of the model. For simplicity we assume that $K_{U}=K_{D}=$ $K$. (The case where $K_{U} \neq K_{D}$ is discussed in Section 6.) We therefore seek $\lambda^{*}$ such that

$$
\pi_{I 0}\left(\lambda^{*}\right)=\pi_{U \Delta}\left(\lambda^{*}\right)
$$

or equivalently,

$$
\pi_{I, 0}\left(\lambda^{*}\right)-\pi_{U, 0}\left(\lambda^{*}\right)=\pi_{U, \Delta}\left(\lambda^{*}\right)-\pi_{U, 0}\left(\lambda^{*}\right) .
$$

To keep notation compact, let $\sigma_{v}=\frac{1}{\sqrt{12}}(\bar{v}-\underline{v})$ and $\sigma_{x}=\frac{1}{\sqrt{12}}(\bar{x}-\underline{x})$. We will make use of the following fact (which is derived in the appendix).

Fact 1 Assume $\lambda \leq(\bar{c}-\underline{c}) \frac{\sigma_{x}}{\sigma_{v}}$. Then

$$
\begin{aligned}
\pi_{I, 0}(\lambda)-\pi_{U, 0}(\lambda) & =\frac{1}{2} \frac{\sigma_{v}^{2}}{\bar{c}-\underline{c}}\left(1-\frac{1}{2} \frac{\lambda}{\bar{c}-\underline{c}} \frac{\sigma_{v}}{\sigma_{x}}\right) \text { and } \\
\pi_{U, \Delta}(\lambda)-\pi_{U, 0}(\lambda) & =\frac{\Delta^{2}}{\bar{c}-\underline{c}} \lambda-\frac{1}{2} \frac{\Delta^{2}}{\bar{c}-\underline{c}}+\mu_{x} \Delta .
\end{aligned}
$$

Observe that the first expression is decreasing in $\lambda$ and the second is increasing in $\lambda$. This leads to the following characterization of industry equilibrium.

Proposition 2 Assume $(\bar{c}-\underline{c}) \frac{\sigma_{x}}{\sigma_{v}} \geq 1$. For all $\bar{c}, \underline{c}, \sigma_{x}, \sigma_{v}, \Delta>0$ with $\underline{c} \geq \Delta$, there exists an industry equilibrium. Further,

$$
\lambda^{*}=\frac{\sigma_{v}^{2}+\Delta^{2}-2(\bar{c}-\underline{c}) \mu_{x} \Delta}{\frac{\sigma_{v}^{2}}{2} \frac{\sigma_{v} / \sigma_{x}}{\bar{c}-\underline{c}}+2 \Delta^{2}}
$$

if the right-hand side of (3) is in $[0,1]$. If the right-hand side of (3) is less than 0, then $\lambda^{*}=0 ;$ if it is greater than 1 , then $\lambda^{*}=1$.

Proof. If $\sigma_{v}^{2} \leq 2(\bar{c}-\underline{c}) \mu_{x} \Delta-\Delta^{2}$, then $\pi_{U, 0}(0) \leq \pi_{U, \Delta}(0)$ and thus, since the left hand side is decreasing in $\lambda$, it follows that $\lambda^{*}=0$. Similarly, if $\sigma_{v}^{2}\left(1-\frac{1}{2} \frac{1}{\bar{c}-\underline{c}} \frac{\sigma_{v}}{\sigma_{x}}\right) \geq 2(\bar{c}-\underline{c}) \mu_{x} \Delta+\Delta^{2}$, 
then $\pi_{U, 0}(1) \geq \pi_{U, \Delta}(1)$, and since the right hand side is increasing in $\lambda$, we must have that $\lambda^{*}=1$. Otherwise, we want to find $\lambda^{*}$ such that

$$
\begin{aligned}
0 & =\left(T S^{U}-T S^{D}\right)\left(\lambda^{*}\right) \\
& =\frac{\sigma_{v}^{2}+\Delta^{2}-2(\bar{c}-\underline{c}) \mu_{x} \Delta}{2(\bar{c}-\underline{c})}-\frac{\lambda^{*}}{2(\bar{c}-\underline{c})}\left(\frac{\sigma_{v} / \sigma_{x}}{\bar{c}-\underline{c}} \frac{\sigma_{v}^{2}}{2}+2 \Delta^{2}\right),
\end{aligned}
$$

which yields the expression in the statement of the proposition.

Proposition 2 is our main result, establishing that there exists a unique industry equilibrium and providing an explicit expression for the proportion of dyads who choose each of the governance structures. As the proposition makes clear, this proportion may well be interior. Recall, however, that our dyads are homogeneous ex ante, so a PRT analysis (taking each dyad in isolation) would prescribe that they all choose the same governance structure. In this sense, the informativeness of the price mechanism can induce heterogeneous behaviors from homogenous dyads. To put this point differently, in this model, the price mechanism can be seen as endogenizing the parameters of the PRT model so that dyads are indifferent between governance structures. In a richer model, with heterogeneous investment costs, almost every dyad would have strict preferences between governance structures, with only the marginal dyad being indifferent.

We are also able to perform some comparative statics. First, when the ex ante level of fundamental uncertainty increases (i.e., $\sigma_{v}$ is higher), the return to investing in acquiring information increases, so $\lambda$ increases to the point where the price mechanism has become sufficiently informative to counteract the increase in $\sigma_{v}$. Second, an increase in noise (i.e., $\sigma_{x}$ is higher) has an identical effect. Finally, an increase in $\Delta$ has two effects. The first is the partial-equilibrium channel through which an increase in the benefits of choosing upstream ownership (and hence investing in cost reduction) makes upstream ownership relatively more appealing, reducing $\lambda$. In an industry equilibrium, however, there is also a price effect. For a fixed fraction $1-\lambda$ of parties that invest in cost reduction, an increase in $\Delta$ makes widgets 
more valuable, which in turn increases demand and hence average prices. Since dyads with upstream ownership purchase widgets over a larger region of the $c_{i}$ space than do dyads with downstream ownership, the former face this increase in average price level relatively more than do dyads with downstream ownership, so the price effect militates towards an increase in $\lambda$. Which of these two effects dominates depends on the parameters of the model.

Proposition 3 Assume $(\bar{c}-\underline{c}) \frac{\sigma_{x}}{\sigma_{v}} \geq 1$. For all $\bar{c}, \underline{c}, \sigma_{x}, \sigma_{v}, \Delta>0$ with $\underline{c} \geq \Delta$ and $\lambda^{*} \in$ $(0,1)$, we have that: (i) $\lambda^{*}$ is increasing in $\sigma_{v}$, (ii) $\lambda^{*}$ is increasing in $\sigma_{x}$, (iii) $\lambda^{*}$ is decreasing in $\mu_{x}$, and (iv) if $\Delta<(\bar{c}-\underline{c}) \mu_{x}$, then $\lambda^{*}$ is decreasing in $\Delta$, otherwise there exists a $\hat{\sigma}_{v}$ satisfying $0 \leq \hat{\sigma}_{v} \leq \frac{2 \Delta(\bar{c}-\underline{c}) \mu_{x}}{3 \Delta+(\bar{c}-\underline{c}) \mu_{x}}$ such that $\lambda^{*}$ is decreasing in $\Delta$ whenever $\sigma_{v}>\hat{\sigma}_{v}$ and increasing in $\Delta$ whenever $\sigma_{v}<\hat{\sigma}_{v}$.

Proof. See appendix.

\section{Implications}

\subsection{PRT Meets REE}

Property-rights theory emphasizes the importance of specific investments for the choice of governance structure: whichever party's investment is more important should own the relevant asset. We can mimic the PRT by eliminating the role of the price mechanism in our model, by supposing that a dyad believes $p(x, v) \equiv p$ for all $\lambda, x, v$ and hence does not recognize that prices are informative.

Fact 2 If $p(x, v) \equiv p$ for all $\lambda, x, v$ then the benefits from choosing $g_{i}=U$ are given by

$$
\pi_{U, 0}-\pi_{U, 0}=\frac{1}{2} \frac{\sigma_{v}^{2}}{\bar{c}-\underline{c}}
$$

and the benefits from choosing $g_{i}=D$ are

$$
\pi_{U, \Delta}-\pi_{U, 0}=\frac{1}{2} \frac{\Delta^{2}+2\left(\mu_{v}-p-\underline{c}\right) \Delta}{\bar{c}-\underline{c}} .
$$


The dyad therefore chooses downstream ownership if $\sigma_{v}^{2}>\Delta^{2}+2\left(\mu_{v}-p-\underline{c}\right) \Delta$, chooses upstream ownership if this inequality is reversed, and is indifferent if the inequality is replaced with an equality. Generically, one of these two inequalities must hold, so the PRT prescription will be either that all dyads are integrated or that all dyads are non-integrated (because the dyads are identical ex ante).

In our model, however, the informativeness of the price mechanism endogenizes the returns to specific investments. In particular, dyads that would have chosen to invest in information acquisition (by choosing downstream ownership of the machine) under the assumptions of Fact 2 may now free-ride on the information contained in the market price and choose instead to invest in cost reduction (by choosing to have upstream ownership of the machine). In fact, in our model, certain governance structures may be sustained in equilibrium only because the price system allows some firms to benefit from the information-acquisition investments of others.

More specifically, as we began to explain after Proposition 2, the equilibrium fraction of dyads choosing downstream ownership in our model, $\lambda^{*}$ in (3), is often interior, not zero or one, as is generally true in a PRT analysis.

Figure 4 illustrates the difference between our analysis and PRT by plotting $\lambda_{P R T}^{*}$ versus our $\lambda^{*}$ from Proposition 2. To plot this figure, we fix $\Delta=1 / 4, \bar{c}-\underline{c}=1$, and $\mu_{x}=0.8$, so that a PRT analysis predicts that all dyads will choose downstream ownership (i.e., $\lambda_{P R T}^{*}=1$ ) if $\sigma_{v}^{2}>0.3375$, all dyads will choose upstream ownership $\left(\lambda_{P R T}^{*}=0\right)$ when $\sigma_{v}^{2}<0.3375$, and dyads will be indifferent $\left(\lambda_{P R T}^{*} \in[0,1]\right)$ when $\sigma_{v}^{2}=0.3375$. The figure shows our equilibrium $\lambda^{*}$ as a function of $\sigma_{v}^{2}$ for three different values of $\sigma_{x}$ (namely, 1/10,1, and 10, with $\lambda^{*}$ falling with $\sigma_{x}$ for a fixed $\sigma_{v}^{2}$ ). Our equilibrium converges to $\lambda^{*}=1$ more slowly (and especially slowly for lower values of $\sigma_{x}$ ). 


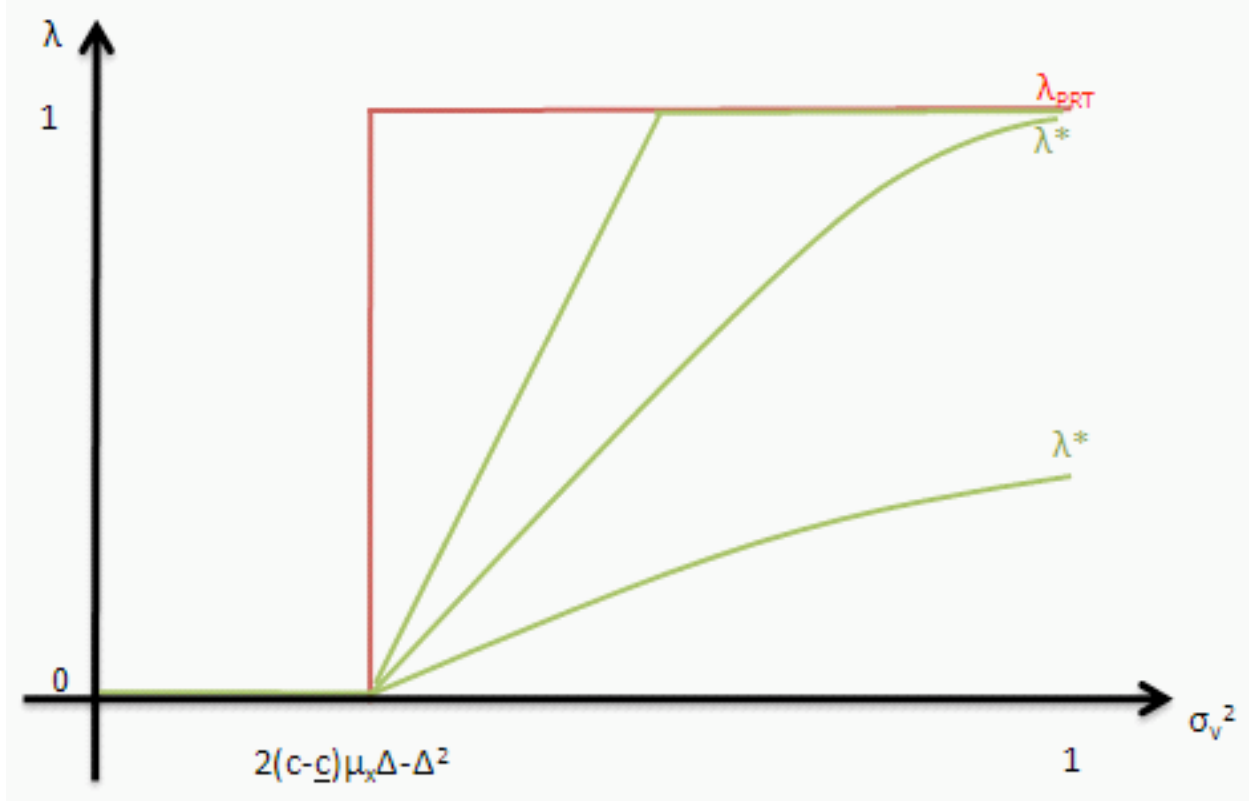

Figure 4: Comparison with PRT

Nonetheless, Figure 4 suggests that empirical tests of PRT that focus solely on the importance of specific investments may be misleading, by failing to consider the role that the price mechanism plays in endogenizing the returns to specific investments. Of course firms may well not be ex ante identical, and thus a mixture of these two effects may determine the choice of governance structure.

\subsection{TCE Meets REE}

Explicitly commenting on Hayek's (1945) discussion of the price mechanism, Williamson (1975: 5) argues that "prices often do not qualify as sufficient statistics and that a substitution of internal organization (hierarchy) for market-mediated exchange often occurs on this account."

Our model allows us to assess those observations, if we can be precise about two things: (i) what it means for prices not to "qualify as sufficient statistics", and (ii) what is meant by "market-mediated exchange." A natural way to think about the first of these is the following. 
Definition 3 The equilibrium informativeness of the price system is the expected reduction in variance $E_{x, v}\left[\sigma_{v}^{2}-\sigma_{v \mid p}^{2}\right]$ that is obtained by conditioning on prices.

In our model, the informativeness of the price system is given by

$$
E\left[\sigma_{v}^{2}-\sigma_{v \mid p}^{2}\right]=\lambda \frac{\sigma_{v}^{2}}{2} \frac{\sigma_{v} / \sigma_{x}}{\bar{c}-\underline{c}}
$$

Naturally, this informativeness is increasing in the fraction of dyads that become informed, $\lambda$. And in our model "market intermediation" also has a natural interpretation: it means relying on information about $v$ from the price mechanism, rather than acquiring it directly (i.e., upstream ownership rather than downstream). In these terms, Williamson's observation can be stated as: when $E\left[\sigma_{v}^{2}-\sigma_{v \mid p}^{2}\right]$ falls, $\lambda^{*}$ increases.

In our model, the direct effect of $\lambda$ runs contrary to Williamson's observation: $E\left[\sigma_{v}^{2}-\sigma_{v \mid p}^{2}\right]$ increases with $\lambda$. But, of course, $\lambda$ is endogenous, so it matters what causes $\lambda$ to increase and what other effects that underlying change has on $E\left[\sigma_{v}^{2}-\sigma_{v \mid p}^{2}\right]$. For example, if $\sigma_{x}$ increases then it can be shown that informativeness decreases and $\lambda^{*}$ increases, as Williamson conjectured. On the other hand, many other changes in exogenous variables can lead simultaneously to an increases in informativeness and an increase in $\lambda^{*}$. That is, it is possible for the price system to "work better" at the same time be used less. For example, it is straightforward to see that an increase in $\mu_{x}$ decreases $\lambda^{*}$ and decreases informativeness. And an increase in $\bar{c}-\underline{c}$ can do likewise, as reported in the following result.

Proposition 4 Assume $(\bar{c}-\underline{c}) \frac{\sigma_{x}}{\sigma_{v}} \geq 1$ and $\lambda^{*} \in(0,1)$. Define $\omega=\frac{1}{\bar{c}-\underline{c}}$. If

$$
\frac{1}{2} \frac{\frac{\sigma_{v}^{2}}{2} \frac{\sigma_{v}}{\sigma_{x}} \omega}{\frac{\sigma_{v}^{2}}{2} \frac{\sigma_{v}}{\sigma_{x}} \omega+\Delta^{2}} \frac{\sigma_{v}^{2}+\Delta^{2}}{2(\bar{c}-\underline{c}) \Delta}<\mu_{x}<\frac{\sigma_{v}^{2}+\Delta^{2}}{2(\bar{c}-\underline{c}) \Delta}
$$

then $\frac{\partial E_{x, v}\left[\sigma_{v}^{2}-\sigma_{v \mid p}^{2}\right]}{\partial \omega}>0$ and $\frac{\partial \lambda^{*}}{\partial \omega}>0$.

Proof. See appendix. 


\subsection{REE Meets PRT}

A final observation is that the theory of the firm sheds new light on the functioning of the price mechanism. Partially-revealing REE models compare the benefits of acquiring information to the exogenously specified costs of acquiring information. As our model shows, what matters is not only these exogenous costs $K_{D}$, but also the opportunity cost of choosing a governance structure that provides incentives to invest in information (namely, the foregone opportunity for cost reduction). To analyze this issue, consider the expression for $\lambda^{*}$ when $K_{U} \neq K_{D}$ :

$$
\lambda^{*}=\frac{\sigma_{v}^{2}+\Delta^{2}-2(\bar{c}-\underline{c})\left(\mu_{x} \Delta+K_{D}-K_{U}\right)}{\frac{\sigma_{v}^{2}}{2} \frac{\sigma_{v} / \sigma_{x}}{\bar{c}-\underline{c}}+2 \Delta^{2}} .
$$

Note the presence of production parameters, such as $\Delta$ and $K_{U}$, which have nothing per se to do with market clearing or price formation. More importantly, note that comparative statics regarding the informativeness of the price mechanism, such as $\partial \lambda^{*} / \partial K_{D}$, can depend on production parameters such as $\Delta$.

In addition to comparative statics that illustrate the potential effects of production parameters on rational-expectations equilibrium, we can also say something about how the production environment affects markets. For example, in GHP we showed that (as in Grossman and Stiglitz, 1980) market thickness depends on $\lambda^{*}$, with concomitant implications for economic efficiency and welfare. In this paper, therefore, market thickness depends on production parameters such as $\Delta$ and $K_{U}$.

\section{Conclusion}

Transaction-cost economics and the property-rights theory have made major contributions to our understanding of why some economic activity occurs within firms. For almost four decades, however, these theories of firms' boundaries have emphasized the hold-up costs 
(and, in the property-rights theory, also the incentive benefits) of non-integration at the transaction level, rather than the functioning of the price mechanism at the market level.

We view firms and the market not only as alternative ways of organizing economic activity, but also as institutions that interact and shape each other. In particular, by combining features of the property-rights theory of firms' boundaries and the rational-expectations theory of the price mechanism, we have developed a model that incorporates two, reciprocal considerations. First, firms operate in the context of the market (specifically, the informativeness of the price mechanism affects parties' optimal governance structures). And second, the market for an intermediate good is made up of firms (specifically, parties' governance structures affect how they buy and sell in this market and hence the informativeness of the price mechanism).

To develop and analyze our model, we have imposed several strong assumptions that might be relaxed in future work. For example, to eliminate the market for machines, we assumed that machines are dyad-specific. Also, as in our paper on price formation (where we analyze individual investors instead of dyads), we ignore the possibility of strategic information transmission before or during the price-formation process.

In addition to relaxing our current assumptions, it would also be interesting to expand this line of argument beyond our current application (to firms' boundaries). For example, a host of internal organizational structures and processes seem likely to be influenced by the information available from the price mechanism (including transfer pricing, resource allocation, and empowerment), but our elemental property-rights model of a dyad is too simple to address these internal issues. Also, as well as investigating the impact of the market on firms, there may be more to say about the impact of firms on the market. For example, it would be interesting to know whether the equilibrium informativeness of the price mechanism is socially efficient and (assuming it is not) what features of firms' production environment facilitate better performance by the market. 


\section{References}

Aghion, Philippe, \& Tirole, Jean. 1997. Formal and Real Authority in Organizations. Journal of Political Economy, 105(1), 1-29.

Alonso, Ricardo, Dessein, Wouter, \& Matouschek, Niko. 2008. When does Coordination require Centralization? American Economic Review, 98(1), 145-179.

Coase, Ronald. 1937. The Nature of the Firm. Economica, 386-405.

Gibbons, Robert, Holden, Richard, \& Powell, Michael. 2009. A Rational Expectations Model of Goods Markets. Massachusetts Institute of Technology working paper.

Grossman, Gene M., \& Helpman, Elhanan. 2002. Integration Versus Outsourcing in Industry Equilibrium. Quarterly Journal of Economics, 85-120.

Grossman, Sanford J. 1981. An Introduction to the Theory of Rational Expectations Under Asymmetric Information. Review of Economic Studies, XLVIII, 541-559.

Grossman, Sanford J., \& Hart, Oliver D. 1986. The Costs and Benefits of Ownership: A Theory of Vertical and Lateral Integration. Journal of Political Economy, 94(4), 691-719.

Grossman, Sanford J., \& Stiglitz, Joseph E. 1976. Information and Competitive Price Systems. American Economic Review, 66(2), 246-253.

Grossman, Sanford J., \& Stiglitz, Joseph E. 1980. On the Impossibility of Informationally Efficient Markets. American Economic Review, 70(4), 393-408.

Hart, Oliver, \& Moore, John. 1990. Property Right and the Nature of the Firm. Journal of Political Economy, 98(6), 1119-1158.

Holmstrom, Bengt, \& Tirole, Jean. 1991. Transfer Pricing and Organizational Form. Journal of Law, Economics and Organization, 7(2), 201-228. 
Klein, Benjamin, Crawford, Robert G., \& Alchian, Armen A. 1978. Vertical Integration, Appropriable Rents, and the Competitive Contracting Process. Journal of Law and Economics, 21(2), 297-326.

Legros, Patrick, \& Newman, Andrew F. 2008. Competing for Ownership. Journal of the European Economic Association, 6(6), 1279-1308.

Legros, Patrick, \& Newman, Andrew F. 2009. A Price Theory of Vertical and Lateral Integration. Boston University working paper.

Milgrom, Paul, \& Roberts, John. 1988. An Economic Approach to Influence Activities in Organizations. American Journal of Sociology, 94, S154-S179.

Rantakari, Heikki. 2008. Governing Adapatation. Review of Economic Studies, 75(4), 12571285.

Williamson, Oliver. 1975. Markets and Hierarchies: Analysis and Antitrust Implications. New York: Free Press.

\section{Appendix}

\subsection{Derivation of Fact 1}

$$
\begin{aligned}
E_{x, v, c_{i}}\left[\pi_{U, 0}(\lambda)\right]-E_{x, v, c_{i}}\left[\pi_{U, 0}(\lambda)\right] & =\frac{1}{2} \frac{1}{\bar{c}-\underline{c}} \frac{1}{\bar{v}-\underline{v}} \frac{1}{\bar{x}-\underline{x}} \int_{\underline{v}}^{\bar{v}} \int_{\underline{x}}^{\bar{x}}\left(v^{2}-\mu_{v \mid p}^{2}\right) d x d v \\
& =\frac{1}{2} \frac{E_{x, v}\left[\sigma_{v \mid p}^{2}\right]}{\bar{c}-\underline{c}}=\frac{1}{2} \frac{\sigma_{v}^{2}}{\bar{c}-\underline{c}}\left(1-\frac{\lambda}{2} \frac{\sigma_{v} / \sigma_{x}}{\bar{c}-\underline{c}}\right),
\end{aligned}
$$

which is continuous and strictly decreasing in $\lambda$ and similarly, 


$$
\begin{aligned}
E_{x, v, c_{i}}\left[\pi_{U, \Delta}(\lambda)\right]-E_{x, v, c_{i}}\left[\pi_{U, 0}(\lambda)\right] & =\frac{\Delta^{2}}{2(\bar{c}-\underline{c})}+\Delta \frac{E_{x, v}\left[\mu_{v \mid p}(x, v)\right]-\underline{c}-E_{x, v}\left[p_{\lambda}(x, v)\right]}{(\bar{c}-\underline{c})} \\
& =\frac{\Delta^{2}}{\bar{c}-\underline{c}} \lambda-\frac{\Delta^{2}}{2(\bar{c}-\underline{c})}+\mu_{x} \Delta
\end{aligned}
$$

which is continuous and strictly increasing in $\lambda$. For the last equalities in these two expressions, we use the following three facts:

$$
\begin{aligned}
E_{x, v}\left[\mu_{v \mid p}\right] & =\mu_{v}, \\
E_{x, v}\left[\sigma_{v \mid p}^{2}\right] & =\sigma_{v}^{2}\left(1-\frac{\lambda}{2} \frac{\sigma_{v} / \sigma_{x}}{\bar{c}-\underline{c}}\right), \text { and } \\
E_{x, v}\left[p_{\lambda}(x, v)\right] & =\mu_{v}+(1-\lambda) \Delta-\mu_{x}(\bar{c}-\underline{c})-\underline{c},
\end{aligned}
$$

which we now prove. First note that when $\lambda \leq(\bar{c}-\underline{c}) \frac{\sigma_{x}}{\sigma_{v}}, p_{\lambda}(x, v)=\sum_{j=1}^{3} 1_{\left\{(x, v) \in R_{\lambda}^{j}\right\}} p_{\lambda}^{j}(x, v)$, where

$$
\begin{aligned}
& p_{\lambda}^{1}(x, v)=(1-\lambda) \frac{\underline{v}+((\bar{c}-\underline{c}) / \lambda) \bar{x}}{2}+(1-\lambda) \Delta-\underline{c}+\frac{1+\lambda}{2} v-\frac{1+\lambda}{2} \frac{\bar{c}-\underline{c}}{\lambda} x \\
& p_{\lambda}^{2}(x, v)=(1-\lambda) \frac{\underline{v}+\bar{v}}{2}+(1-\lambda) \Delta-\underline{c}+\lambda v-(\bar{c}-\underline{c}) x \\
& p_{\lambda}^{3}(x, v)=(1-\lambda) \frac{((\bar{c}-\underline{c}) / \lambda) \underline{x}+\bar{v}}{2}+(1-\lambda) \Delta-\underline{c}+\frac{1+\lambda}{2} v-\frac{1+\lambda}{2} \frac{\bar{c}-\underline{c}}{\lambda} x,
\end{aligned}
$$

and

$$
\begin{aligned}
& R_{\lambda}^{1}=\left\{(x, v): p_{\lambda}^{1}(x, v) \leq p_{\lambda}^{1}(\bar{x}, \bar{v})\right\} \\
& R_{\lambda}^{2}=\left\{(x, v): p_{\lambda}^{2}(\bar{x}, \bar{v})<p_{\lambda}^{2}(x, v) \leq p_{\lambda}^{2}(\underline{x}, \underline{v})\right\} \\
& R_{\lambda}^{3}=\left\{(x, v): p_{\lambda}^{3}(\underline{x}, \underline{v})<p_{\lambda}^{3}(x, v)\right\} .
\end{aligned}
$$


We can rewrite the prices as

$$
\begin{aligned}
& p_{\lambda}^{1}(x, v)=p_{\lambda}^{2}(x, v)-\frac{1-\lambda}{2}\left[(\bar{v}-v)-\frac{\bar{c}-\underline{c}}{\lambda}(\bar{x}-x)\right] \\
& p_{\lambda}^{2}(x, v)=(1-\lambda) \frac{\underline{v}+\bar{v}}{2}+(1-\lambda) \Delta-\underline{c}+\lambda v-(\bar{c}-\underline{c}) x \\
& p_{\lambda}^{3}(x, v)=p_{\lambda}^{2}(x, v)+\frac{1-\lambda}{2}\left[(v-\underline{v})-\frac{\bar{c}-\underline{c}}{\lambda}(x-\underline{x})\right] .
\end{aligned}
$$

For simplicity of notation, define $R_{\lambda}^{j}(v)=\left\{x:(x, v) \in R_{\lambda}^{j}\right\}$. That is

$$
\begin{aligned}
& R_{\lambda}^{1}(v)=\left[\bar{x}-\frac{\lambda}{\bar{c}-\underline{c}}(\bar{v}-v), \bar{x}\right] \\
& R_{\lambda}^{2}(v)=\left[\underline{x}+\frac{\lambda}{\bar{c}-\underline{c}}(v-\underline{v}), \bar{x}-\frac{\lambda}{\bar{c}-\underline{c}}(\bar{v}-v)\right) \\
& R_{\lambda}^{3}(v)=\left[\underline{x}, \underline{x}+\frac{\lambda}{\bar{c}-\underline{c}}(v-\underline{v})\right) .
\end{aligned}
$$

Finally, note that

$$
\begin{aligned}
& \mu_{v \mid p}^{1}(x, v)=\mu_{v}-\frac{1}{2}\left[(\bar{v}-v)-\frac{\bar{c}-\underline{c}}{\lambda}(\bar{x}-x)\right] \\
& \mu_{v \mid p}^{2}(x, v)=\mu_{v} \\
& \mu_{v \mid p}^{3}(x, v)=\mu_{v}+\frac{1}{2}\left[(v-\underline{v})-\frac{\bar{c}-\underline{c}}{\lambda}(x-\underline{x})\right] .
\end{aligned}
$$

Claim $1 \quad E_{x, v}\left[\mu_{v \mid p}\right]=\mu_{v}$

Proof. Follows directly from the Law of Iterated Expectations.

Claim $2 E_{x, v}\left[\sigma_{v \mid p}^{2}\right]=\sigma_{v}^{2}\left(1-\frac{\lambda}{2} \frac{\sigma_{v} / \sigma_{x}}{\bar{c}-\underline{c}}\right)$ 
Proof. Here, we want to compute

$$
\begin{aligned}
E_{x, v}\left[\sigma_{v \mid p}^{2}\right]= & \frac{1}{\bar{v}-\underline{v}} \frac{1}{\bar{x}-\underline{x}} \int_{\underline{v}}^{\bar{v}} \int_{\bar{x}-\frac{\lambda}{\bar{c}-\underline{c}}(\bar{v}-v)}^{\bar{x}}\left(v^{2}-\left(\mu_{v \mid p}^{1}\right)^{2}\right) d x d v \\
& +\frac{1}{\bar{v}-\underline{v}} \frac{1}{\bar{x}-\underline{x}} \int_{\underline{v}}^{\bar{v}} \int_{\underline{x}+\frac{\lambda}{\bar{c}-\underline{c}}(v-\underline{v})}^{\bar{x}-\frac{\lambda}{\bar{c}-\underline{c}}(\bar{v}-v)}\left(v^{2}-\left(\mu_{v}\right)^{2}\right) d x d v \\
& +\frac{1}{\bar{v}-\underline{v}} \frac{1}{\bar{x}-\underline{x}} \int_{\underline{v}}^{\bar{v}} \int_{\underline{x}}^{\underline{x}+\frac{\lambda}{\bar{c}-\underline{c}}(v-\underline{v})}\left(v^{2}-\left(\mu_{v \mid p}^{3}\right)^{2}\right) d x d v
\end{aligned}
$$

If we substitute and rearrange, this becomes

$$
\begin{aligned}
E_{x, v}\left[\sigma_{v \mid p}^{2}\right]= & \frac{1}{\bar{v}-\underline{v}} \frac{1}{\bar{x}-\underline{x}} \int_{\underline{v}}^{\bar{v}} \int_{\underline{x}}^{\bar{x}}\left(v^{2}-\left(\mu_{v}\right)^{2}\right) d x d v \\
& +\frac{1}{\bar{v}-\underline{v}} \frac{1}{\bar{x}-\underline{x}} \int_{\underline{v}}^{\bar{v}} \int_{\bar{x}-\frac{\lambda}{\bar{c}-\underline{c}}(\bar{v}-v)}^{\bar{x}}\left(\mu_{v}\left[(\bar{v}-v)-\frac{\bar{c}-\underline{c}}{\lambda}(\bar{x}-x)\right]-\frac{1}{4}\left[(\bar{v}-v)-\frac{\bar{c}-\underline{c}}{\lambda}(\bar{x}-x)\right]^{2}\right. \\
& -\frac{1}{\bar{v}-\underline{v}} \frac{1}{\bar{x}-\underline{x}} \int_{\underline{v}}^{\bar{v}} \int_{\underline{x}}^{\underline{x}+\frac{\lambda}{\bar{c}-\underline{c}}(v-\underline{v})}\left(\mu_{v}\left[(v-\underline{v})-\frac{\bar{c}-\underline{c}}{\lambda}(x-\underline{x})\right]+\frac{1}{4}\left[(v-\underline{v})-\frac{\bar{c}-\underline{c}}{\lambda}(x-\underline{x})\right]\right.
\end{aligned}
$$

Integrating, we get

$$
\begin{aligned}
E_{x, v}\left[\sigma_{v \mid p}^{2}\right] & =\sigma_{v}^{2}+\frac{\sigma_{v}}{\sigma_{x}} \frac{\lambda}{\bar{c}-\underline{c}}\left(\mu_{v} \frac{(\bar{v}-\underline{v})}{6}-\frac{1}{4} \sigma_{v}^{2}\right)-\frac{\sigma_{v}}{\sigma_{x}} \frac{\lambda}{\bar{c}-\underline{c}}\left(\mu_{v} \frac{(\bar{v}-\underline{v})}{6}+\frac{1}{4} \sigma_{v}^{2}\right) \\
& =\sigma_{v}^{2}\left(1-\frac{\lambda}{2} \frac{\sigma_{v} / \sigma_{x}}{\bar{c}-\underline{c}}\right)
\end{aligned}
$$

which was the original claim.

Claim $3 E_{x, v}\left[p_{\lambda}(x, v)\right]=\mu_{v}+(1-\lambda) \Delta-\mu_{x}(\bar{c}-\underline{c})-\underline{c}$ 
Proof. Similarly as above,

$$
\begin{aligned}
E_{x, v}\left[p_{\lambda}(x, v)\right]= & \frac{1}{\bar{v}-\underline{v}} \frac{1}{\bar{x}-\underline{x}} \int_{\underline{v}}^{\bar{v}} \int_{\bar{x}-\frac{\lambda}{\bar{c}-\underline{c}}(\bar{v}-v)}^{\bar{x}} p_{\lambda}^{1}(x, v) d x d v \\
& +\frac{1}{\bar{v}-\underline{v}} \frac{1}{\bar{x}-\underline{x}} \int_{\underline{v}}^{\bar{v}} \int_{\underline{x}+\frac{\lambda}{\bar{c}-\underline{c}}(v-\underline{v})}^{\bar{x}-\frac{\lambda}{\bar{c}-\underline{c}}(\bar{v}-v)} p_{\lambda}^{2}(x, v) d x d v \\
& +\frac{1}{\bar{v}-\underline{v}} \frac{1}{\bar{x}-\underline{x}} \int_{\underline{v}}^{\bar{v}} \int_{\underline{x}}^{\underline{x}+\frac{\lambda}{\bar{c}-\underline{c}}(v-\underline{v})} p_{\lambda}^{3}(x, v) d x d v .
\end{aligned}
$$

If we substitute and rearrange, we get

$$
\begin{aligned}
E_{x, v}\left[p_{\lambda}(x, v)\right]= & \frac{1}{\bar{v}-\underline{v}} \frac{1}{\bar{x}-\underline{x}} \int_{\underline{v}}^{\bar{v}} \int_{\underline{x}}^{\bar{x}} p_{\lambda}^{2}(x, v) d x d v \\
& -\frac{1}{\bar{v}-\underline{v}} \frac{1}{\bar{x}-\underline{x}} \int_{\underline{v}}^{\bar{v}} \int_{\bar{x}-\frac{\lambda}{\bar{c}-\underline{c}}(\bar{v}-v)}^{\bar{x}} \frac{1-\lambda}{2}\left[(\bar{v}-v)-\frac{\bar{c}-\underline{c}}{\lambda}(\bar{x}-x)\right] d x d v \\
& +\frac{1}{\bar{v}-\underline{v}} \frac{1}{\bar{x}-\underline{x}} \int_{\underline{v}}^{\bar{v}} \int_{\underline{x}}^{\underline{x}+\frac{\lambda}{\bar{c}-\underline{c}}(v-\underline{v})} \frac{1-\lambda}{2}\left[(v-\underline{v})-\frac{\bar{c}-\underline{c}}{\lambda}(x-\underline{x})\right] d x d v
\end{aligned}
$$

or since the last two expressions are equal but with opposite signs,

$$
E_{x, v}\left[p_{\lambda}(x, v)\right]=\mu_{v}+(1-\lambda) \Delta-(\bar{c}-\underline{c}) \mu_{x}-\underline{c},
$$

which is the desired expression

\subsection{Derivation of Fact 2}

Explicit computation yields the following benefit for choosing $g=U$ 


$$
\begin{aligned}
E\left[\pi_{U, 0}\right]-E\left[\pi_{U, 0}\right]= & \frac{1}{\bar{c}-\underline{c}} \frac{1}{\bar{v}-\underline{v}} \frac{1}{\bar{x}-\underline{x}} \int_{\underline{v}}^{\bar{v}} \int_{\underline{x}}^{\bar{x}} \int_{\underline{c}}^{v-p}\left(v-p-c_{i}\right) d c_{i} d x d v \\
& -\frac{1}{\bar{c}-\underline{c}} \frac{1}{\bar{v}-\underline{v}} \frac{1}{\bar{x}-\underline{x}} \int_{\underline{v}}^{\bar{v}} \int_{\underline{x}}^{\bar{x}} \int_{\underline{c}}^{\mu_{v}-p}\left(v-p-c_{i}\right) d c_{i} d x d v \\
= & \frac{1}{2} \frac{1}{\bar{c}-\underline{c}} \frac{1}{\bar{v}-\underline{v}} \frac{1}{\bar{x}-\underline{x}} \int_{\underline{v}}^{\bar{v}} \int_{\underline{x}}^{\bar{x}}\left(v-\mu_{v}\right)^{2} d x d v \\
= & \frac{1}{2} \frac{\sigma_{v}^{2}}{\bar{c}-\underline{c}},
\end{aligned}
$$

and similarly the benefits for choosing $g=D$ are

$$
\begin{aligned}
E\left[\pi_{U, \Delta}\right]-E\left[\pi_{U, 0}\right]= & \frac{1}{\bar{c}-\underline{c}} \frac{1}{\bar{v}-\underline{v}} \frac{1}{\bar{x}-\underline{x}} \int_{\underline{v}}^{\bar{v}} \int_{\underline{x}}^{\bar{x}} \int_{\underline{c}}^{\mu_{v}-p+\Delta}\left(v-p+\Delta-c_{i}\right) d c_{i} d x d v \\
& -\frac{1}{\bar{c}-\underline{c}} \frac{1}{\bar{v}-\underline{v}} \frac{1}{\bar{x}-\underline{x}} \int_{\underline{v}}^{\bar{v}} \int_{\underline{x}}^{\bar{x}} \int_{\underline{c}}^{\mu_{v}-p}\left(v-p-c_{i}\right) d c_{i} d x d v \\
= & \frac{1}{\bar{c}-\underline{c}} \frac{1}{\bar{v}-\underline{v}} \frac{1}{\bar{x}-\underline{x}} \int_{\underline{v}}^{\bar{v}} \int_{\underline{x}}^{\bar{x}}\left((v-p) \Delta-\underline{c} \Delta+\frac{\Delta^{2}}{2}\right) d x d v \\
= & \frac{1}{2} \frac{\Delta^{2}+2\left(\mu_{v}-p-\underline{p}\right) \Delta}{\bar{c}-\underline{c}} .
\end{aligned}
$$

\subsection{Omitted Proofs}

Proof of Proposition 3. To establish that $\lambda^{*}$ is increasing in $\sigma_{v}$, note that at $\lambda=0$, the gains from choosing integration (and hence becoming informed) instead of non-integration (and hence enjoying a cost reduction) are given by

$$
\left(T S^{U}-T S^{D}\right)(\lambda=0)=\frac{\sigma_{v}^{2}+\Delta^{2}-2(\bar{c}-\underline{c}) \mu_{x} \Delta}{2(\bar{c}-\underline{c})}
$$

and at $\lambda=1$, the gains from choosing integration over non-integration are

$$
\left(T S^{U}-T S^{D}\right)(\lambda=1)=\frac{\sigma_{v}^{2}}{2(\bar{c}-\underline{c})}\left(1-\frac{1}{2} \frac{\sigma_{v} / \sigma_{x}}{\bar{c}-\underline{c}}\right)-\frac{\Delta^{2}+2(\bar{c}-\underline{c}) \mu_{x} \Delta}{2(\bar{c}-\underline{c})}
$$


Since we are at an interior solution, $\left(T S^{U}-T S^{D}\right)(\lambda=0)>0$ and $\left(T S^{U}-T S^{D}\right)(\lambda=1)<$ 0. Next, note that $\left(T S^{U}-T S^{D}\right)(\lambda=0)$ is increasing in $\sigma_{v}$ and $\left(T S^{U}-T S^{D}\right)(\lambda=1)$ is increasing in $\sigma_{v}$ if $(\bar{c}-\underline{c}) \frac{\sigma_{x}}{\sigma_{v}}>\frac{3}{4}$, which is true since $(\bar{c}-\underline{c}) \frac{\sigma_{x}}{\sigma_{v}}>1$. Since $\left(T S^{U}-T S^{D}\right)(\lambda)$ is linear in $\lambda$, this then implies that $\lambda^{*}$ is increasing in $\sigma_{v}$.

The comparative statics with respect to $\mu_{x}$ and $\sigma_{x}$ are straightforward. Finally, note that

$$
\frac{\partial \lambda^{*}}{\partial \Delta}=2 \frac{\Delta-(\bar{c}-\underline{c}) \mu_{x}-2 \lambda^{*} \Delta}{\frac{\sigma_{v} / \sigma_{x}}{\bar{c}-\underline{c}} \frac{\sigma_{v}^{2}}{2}+2 \Delta^{2}}
$$

When $\Delta<(\bar{c}-\underline{c}) \mu_{x}$, this is clearly negative. Otherwise, if, note that at $\sigma_{v}=0$, $2 \lambda^{*} \Delta=\Delta-2(\bar{c}-\underline{c}) \mu_{x}$, so this expression is positive. For $\sigma_{v}>\frac{2 \Delta(\bar{c}-\underline{c}) \mu_{x}}{3 \Delta+(\bar{c}-\underline{c}) \mu_{x}}$, the expression is negative. Since $\lambda^{*}$ is increasing in $\sigma_{v}$, this implies that there is a cutoff value $0 \leq \hat{\sigma}_{v} \leq$ $\frac{2 \Delta(\bar{c}-\underline{c}) \mu_{x}}{3 \Delta+(\bar{c}-\underline{c}) \mu_{x}}$, a function of the other parameters of the model, for which $\sigma_{v}<\hat{\sigma}_{v}$ implies that $\frac{\partial \lambda^{*}}{\partial \Delta}>0$ and $\sigma_{v}>\hat{\sigma}_{v}$ implies that $\frac{\partial \lambda^{*}}{\partial \Delta}<0$.

Proof of Proposition 4. Note that

$$
\frac{\partial \lambda^{*}}{\partial \omega}=\frac{2 \omega^{-2} \mu_{x} \Delta-\frac{\sigma_{v}^{2}}{2} \frac{\sigma_{v}}{\sigma_{x}} \lambda^{*}}{\frac{\sigma_{v}^{2}}{2} \frac{\sigma_{v}}{\sigma_{x}} \omega+2 \Delta^{2}}>0
$$

whenever

$$
\frac{1}{2} \frac{\frac{\sigma_{v}^{2}}{2} \frac{\sigma_{v}}{\sigma_{x}} \omega}{\frac{\sigma_{v}^{2}}{\sigma_{x}} \omega} \frac{\sigma_{v}}{\sigma_{x}} \frac{\sigma_{v}^{2}+\Delta^{2}}{2 \omega^{-1} \Delta}<\mu_{x}<\frac{\sigma_{v}^{2}+\Delta^{2}}{2 \omega^{-1} \Delta}
$$

and

$$
\frac{\partial E_{x, v}\left[\sigma_{v}^{2}-\sigma_{v \mid p}^{2}\right]}{\partial \omega}=\frac{\sigma_{v}^{2}}{2} \frac{\sigma_{v}}{\sigma_{x}}\left(\frac{2 \Delta^{2}}{\frac{\sigma_{v}^{2}}{2} \frac{\sigma_{v}}{\sigma_{x}} \omega+2 \Delta^{2}} \lambda^{*}+\frac{2 \omega^{-1} \mu_{x} \Delta}{\frac{\sigma_{v}^{2}}{2} \frac{\sigma_{v}}{\sigma_{x}} \omega+2 \Delta^{2}}\right)>0
$$

so that equilibrium informativeness is always increasing in $\omega$. 